\title{
An assessment of women's awareness and knowledge about cervical cancer and screening and the barriers to cervical screening in Ogun State, Nigeria.
}

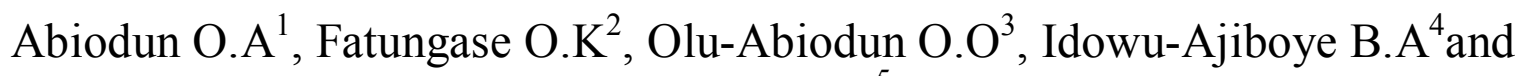 \\ Awosile J.O $\mathrm{O}^{5}$ \\ 1. Department of Community Medicine, Babcock University. Ilishan, Nigeria. \\ 2. Ogun State Agency for the Control of AIDS, Abeokuta, Nigeria. \\ 3. School of Nursing, Ijebu-Ode. Ogun State, Nigeria. \\ 4. Centre for Research in Reproductive Health, Sagamu, Nigeria. \\ 5. Postgraduate Health Research Institute, Olabisi Onabanjo University Teaching Hospital, Sagamu,Nigeria.
}

\begin{abstract}
This is an insight into women's understanding of cervical cancer risk factors, symptomatology, prevention and screening. Quantitative Data was collected using questionnaires administered to 2000 women (aged 20 to 64 years) who were selected by multi-stage sampling technique across the 20 local government areas in Ogun State, Nigeria. The study showed thatthe awareness of cervical cancer and screening was very low (6.5\% and $4.8 \%$ respectively). The knowledge about cervical and screening was very poor. Only $2.3 \%$ of the women could identify a virus as the cause of cervical cancer while $4.1 \%$ identified cervical screening as a way to prevent cervical cancer. $97.7 \%$ and $97.9 \%$ had no or poor knowledge of risk factors and knowledge of symptoms of cervical cancer. $90.5 \%$ identified lack of awareness as the barrier to uptake of cervical screening. $1.4 \%$ of the women have had cervical screening done.In order to step up the campaign for the control of cervical cancer in Nigeria, it is therefore very important to concentrate much of the effort on creation of awareness and enhancing the knowledge of women about cervical cancer and screening.
\end{abstract}

Keywords: cervical cancer, cervical screening, barriers.

\section{Introduction}

Cervical cancer is a leading cause morbidity and mortality in women especially in sub-Saharan African countries [1]. Globally, it is the second commonest cancer in women with 529,828 new cases being diagnosed every year; $85 \%$ of which are in developing countries [1]. It is estimated that more than 275,000 women die yearly from the disease in developing countries [1]. Most of these women are from the developing countries.

The burden of cervical cancer in Nigeria is huge. Nigeria has a population of over 40 million women aged 15 and above who are at risk of cervical cancer. It accounts for $63 \%$ of genital cancers. Current estimates indicate that every year 14,550 women are diagnosed with cervical cancer and 9,659 die from the disease. It is Projected that in 2025, there will be 22,914 new cervical cancer cases and 15,251 cervical cancer deaths in Nigeria [1]. The national Age standardized incidence rate for cervical cancer in Nigeria is estimated to be 33.0 cases per 100,000 women per year [1].

The most important risk factor in developing countries is infrequent cervical screening or lack of accessible cervical screening services. Another very important risk factor in the development of cervical cancer is infection with a high-risk strain of human papilloma virus. The virus-cancer link works by triggering alterations in the cells of the cervix, which can lead to the development of cervical intraepithelial neoplasia, which can then result in cancer. Women who have many sexual partners (or who have sex with men or women who had many other partners) have a greater risk [2]. More than 150 types (some sources indicate more than 200 subtypes) of HPV are acknowledged to exist [3].Fifteen (15) of them are classified as high-risk types and 12 as low-risk. Types 16 and 18 are generally acknowledged to cause about $70 \%$ of cervical cancer cases. Together with type 31, they are the prime risk factors for cervical cancer [3]. Genital warts are caused by various strains of HPV which are usually not related to cervical cancer. Other cofactors that increase the risk of cancer of the cervix are smoking, HIV infection, Chlamydia infection, dietary factors, hormonal contraception, multiple pregnancies, exposure to the hormonal drug diethylstilbestrol (DES) and a family history of cervical cancer [2].

Premalignant changes have no symptoms and are usually not noticeable on visual examination [4].The early stages of cervical cancer may be completely asymptomatic [4]. However; by the time it is large enough to detect visually it is usually symptomatic with abnormal bleeding. Often this abnormal bleeding occurs after sexual intercourse. Later on there may be watery or foul discharge that will be noticeable and resistant to most treatments for the usual vaginal infections [4]. It may spread to the ureters and result in renal failure, coma and death. If the cancer grows into the pelvic wall it will press on the nerves that go to the leg and cause unremitting 
leg pain. These are symptoms of an advanced cancer. Cervical cancers usually do not spread early. They tend to be slow growing and cause most of their problems in the pelvis. In advanced disease, metastases may be present in the abdomen, lungs or elsewhere. Symptoms of advanced cervical cancer may include: loss of appetite, weight loss, fatigue, pelvic pain, back pain, leg pain, and swollen leg. Heavy bleeding from the vagina, leaking of urine or feces from the vagina and bone fractures are other symptoms of late presentation [5].

Cancer of the cervix can be prevented by providing widespread and regular cervical screening services for all women who have been sexually active. This is done by The Pap Smear test or the Visual Inspection of the Acetic Acid painted cervix (VIA) which is affordable and more sensitive. Vaccination against the Human Papilloma Virus in women before the onset of sexual activity also prevents the disease. This is however very expensive at the moment. The One-Visit Approach - screening with VIA by trained personnel and provision of cryotherapy for obvious mild to moderate cervical dysplasia is recommended for developing countries [6-10].

Cervical cancer competes for scarce resources with other diseases like HIV and AIDS, Tuberculosis and Malaria. Although, cervical cancer is preventable and curable when detected early, its burden continues to rise in Nigeria. Many studies on cervical cancer have been done in Nigeria but these are often hospital based and involving limited areas as towns. This study is community based involving a whole State. It assesses the awareness and knowledge about cervical cancer and cervical screening. It also seeks to identify the possible barriers to cervical screening.

\subsection{Study Area}

\section{Methodology}

Ogun State is entirely in the tropics. Located in the Southwest Zone of Nigeria with a total land area of 16,409.26 square kilometers, it is bounded on the West by the Benin Republic, on the South by Lagos State and the Atlantic Ocean, on the East by Ondo State, and on the North by Oyo and Osun States. It is situated between Latitude $6.2^{\circ} \mathrm{N}$ and $7.8^{\circ} \mathrm{N}$ and Longitude $3.0^{\circ} \mathrm{E}$ and $5.0^{\circ} \mathrm{E}$. There are 20 Local Government Areas and 236 Political Wards in Ogun State, Nigeria.

\subsection{Study Population}

The projected Population of Ogun State, Nigeria is about 4,280,090. The population of women between the ages of 20 and 64 years was put at 921,712 with an annual growth rate of $2.8 \%$. The projected Population of women between the ages of 20 and 64 (ages with the most significant risk of cervical changes) in Ogun State is about $1,058,184$.

\subsection{Study Design}

The study design is cross- sectional.

\subsection{Sampling}

The sample size was calculated using the formulae for estimating prevalence in a descriptive study where study population is more than 10,000 [11] based on a prevalence of $52.8 \%$ which is the proportion women who were aware of cervical screening in Owerri, south-east, Nigeria[12] and a worst expected frequency of $\pm 5 \%$ at a confidence level of $95 \%$. The minimum required sample size was 383. A sample size of 2,000 was used. Using proportionate allocation based on relatively populations the sample sizes were allocated to each of the 20 local government areas. Multistage sampling technique was used to recruit participants.Four (4) wards were selected by simple random process via balloting in each of the 20 Local government areas in the State. The list of streets in each of the selected wards was obtained from the National Population Commission (NPC). Five (5) streets per ward were randomly selected by balloting. The sampling fraction was used to determine the number of houses to be visited per street. Systematic random sampling was used to select houses on each street. The first eligible consenting woman in each of the houses was recruited to participate in the study. If no consenting eligible woman was found in a house, eligible participant were sought from the next house.

\subsection{Data collection}

An interviewer administered questionnaire was administered by trained Assistants. The questionnaire was adapted from "Planning and Implementing a cervical cancer prevention and control programme" (a publication of the program for Appropriate Technology in Health- PATH). The questionnaire was to Yoruba (the local language). It was pretested in a local government area in Oyo State, a State with similar characteristic as Ogun State and adjusted to suite the Research needs. The questionnaire assessed the level of awareness and knowledge of cervical cancer and screening and the barriers to uptake of screening services among women. 


\subsection{Data Analysis}

The data obtained were double-entered into using Microsoft Excel package and screened. Analysis was done using The Statistical Package for Social Sciences (SPSS) Software. Data are presented in the form of frequencies and percentages.

\subsection{Profile of the women interviewed}

\section{Results}

A total of 2,000 women were interviewed. Their ages ranged from 20 to 64 years with an average age of $32.7 \pm 10.6$ years. Married women constituted $76.3 \%$ of the women while $19.5 \%$ were single. Those who were single divorced made up the remaining $4.2 \%$. Among the married women, rate of Polygamy was $35.4 \%$. In terms of highest level of education completed, $42.4 \%$ of the women completed secondary school while $27.8 \%$ completed primary school only. The Primary School completion rate is $85.6 \%$, while $14.4 \%$ of the women had never completed any level of schooling. Self-employed petty trading and peasant farming are the most occupation engaging $69.1 \%$ of the women, while $10.7 \%$ of them were students and $9.4 \%$ were in paid employment. The average monthly earning was $9,143.73 \pm 13,174.21$ Naira $(\approx 57.14$ USD). Two thirds of the women earned less than 2 USD per day.

The mean age at first sexual intercourse was $20.2 \pm 3.5$ years with a range of 10 to 35 years while the mean age at first marriage was $22.3 \pm 3.9$ years with a range of 12 to 43 years. Modern contraceptive use rate was $21.9 \%$ with $45.2 \%$ of users using injectable contraception, $15.8 \%$ using oral pills and $14.95 \%$ using the male condoms.

\subsection{Awareness of cervical cancer and screening}

The majority of the women interviewed were not aware of cervical cancer or screening. As shown in Table 1, the level of awareness of cervical cancer and screening were $6.5 \%$ and $4.8 \%$ respectively. Among those that were aware of cervical and screening the commonest sources of becoming aware were Health professionals, the mass media and through friends and relatives.

\subsection{Knowledge about cervical cancer and screening}

Out of the 2,000 women interviewed, only $45(2.3 \%)$ could currently link cervical cancer to a virus as its causative agent. Over $95 \%$ of the women did not have an idea of the cause. The other women suggested evil spirits, unclean water source and poor hygiene as the cause. The majority of the women were unable to correctly identify the risk factors for cervical cancer. According to Table 2, over $95 \%$ were unable to correctly identify family history, cigarette smoking, multiple sexual partners, hormonal contraception usage, poor diet and HIV/AIDS as risk factors for cervical cancer. They were unable to identify the symptoms of cervical cancer. Only $4.1 \%$ and $3.1 \%$ respectively of the women could identify screening and vaccination as ways to prevent cervical cancer while $2.4 \%$ of them said that proper and regular condom use was a means to prevent cervical cancer.

Table 3 shows that the knowledge of cervical screening is quite poor. Eighty two (4.1\%) of the 2,000 women answered correctly that screening could prevent cervical cancer while only $4.0 \%$ of the women knew that screening would detect early disease. In this same vein, only $4.2 \%$ of the women knew that the disease can be cured if detected early. Seventy four (3.7\%) of the women knew that cervical screening should be done at regular intervals while $95.3 \%$ had no idea at all.

\subsection{Barriers to cervical screening}

Twenty seven (1.4\%) of the 2,000 women had done a cervical screening as at the time of the survey. The major barrier to cervical screening by the women who had not done cervical screening was lack of awareness as noted by $95.5 \%$. The other barriers were lack of interest (1.8\%), lack of access to screening services $(0.8 \%)$, cost $(0.8 \%)$ and poor quality if services $(0.5 \%)$.

\section{Discussion}

Results of the study indicated that cervical cancer is a relatively unknown disease in Ogun State, Nigeria. The level of awareness (6.5\%) is comparable to the levels of awareness found in the general female population in some other parts of south west, Nigeria and indeed Nigeria [13]. Ogun and Bejide estimated the level of awareness in general female population in south west Nigeria to be $15 \%$. [13] Low levels of awareness were also found in gwagwalada, Abuja and Aba, south eaten Nigeria $[14,15]$. Other studies especially among health care workers and students of higher institutions of learning showed a high level of awareness $[14,16$, 17].Awareness among healthcare workers was high; $99 \%$ in Lagos [16].87\% among female nurses in Nnewi [18] and over $65 \%$ of female workers in a tertiary health institution in Benin [19].Seventy one percent (71\%) of undergraduates in Ibadan, Nigeria were aware of cervical cancer [17]. The awareness was found higher among 
medical students [17]. However, only $33 \%$ of female students in a South African university were found to be aware of cervical cancer [20].

Cervical screening is also not well known. The level of awareness $(4.8 \%)$ is very lowwhen compared with findings from south-East, Nigeria. Awareness levels of $16 \%$ and $15.5 \%$ respectively of women in Aba and Enugu both in south-eastern Nigeria were reported for cervical cancer screening [15, 21]. Another study in Owerri, also south-eastern Nigeria found a level of awareness of 52.8\% [12]. Aba, Enugu and Owerri are an urban city. In Enugu, the awareness significantly varied with the level of educational attainment [21]. High level of awareness about cervical cancer was also found in North-west Cameroon [22]. Higher levels of awareness were found among students and healthcare workers. Sixty four percent (64\%) of female workers in a tertiary health institution in Benin, Nigeria were aware of cervical screening [19]. Ninety one percent (91\%) of health care workers in Lagos were aware of pap smear [16] Though only $31 \%$ of female students in a higher institution South Africa were aware of cervical screening [20].

The knowledge about cervical cancer and screening was extremely poor. The overwhelming majority of the respondents could not correctly identify the risk factors, symptoms and means of prevention of cervical cancer. The majority knew nothing about cervical screening. More than $95 \%$ respondent had very poor knowledge of cervical cancer and screening. The low levels of awareness have to be greatly responsible for the poverty of knowledge about cervical cancer and screening. In a general female (ages between 20 and 65 years)population in Ibadan, Nigeria, Ogun and Bejide found that that $85 \%$ of women demonstrated very poor knowledge of cervical cancer and screening [13]. Health workers and students have been shown to better knowledge. A study among 230 female respondents in the various health professions including doctors, pharmacists, nurses and laboratory technologists in Murtala Mohammed Specialist hospital, Kano Nigeria, showed that over $60 \%$ of the respondents were able to correctly identify all the important risk factors associated with cervical cancer, while a similar figure knew the important signs and symptoms of the disease [23]. Whereas, $92 \%$ of the Nurses in a study in a teaching hospital in Lagos, Nigeria were aware of the causative organism of cervical cancer- human papilloma virus [16].In a descriptive cross sectional study of 137 nurses at a regional hospital in Tanzania, less than half of the nurses had adequate knowledge regarding cervical cancer. The majority did not know screening intervals and a few were aware of HPV vaccine [24]. Among Cameroon health workers, $58 \%$ were able to identify the most important etiological factors and $90 \%$ knew that screening would prevent cervical cancer [25].Among female students of a south African university a third (32\%) and over a quarter (26\%) knew about the HPV virus and multiple sexual partners, respectively, as risk factors for cervical cancer and a third (33\%) knew that Pap smear is used for detection or prevention of cervical cancer [20]. Less than 10\% of market women in Lagos had correct information about Pap smear [26].

In Kolkata, India, only 5\%of women in have good knowledge of the Pap test [27]. The result is only marginal better even in some developed parts of the world. According to the US National Cancer Institute's 2005 Health Information National Trends survey, only $20 \%$ had heard of the link between human papilloma virus (HPV) infection and cervical cancer [28].

Cervical screening is not often practised as a health seeking behaviour. The high percentage of unscreened women $(98.6 \%)$ of women who had not had cervical screening done serves as a pointer to the large extent to which cases of cervical cancer go without being detected at least till advanced diseases have emerged. This affirms the WHO assertion many years ago that in most developing countries, only $5 \%$ of the women at any point in time had been screened for cervical cancer [29,30]. The figure is also in tune (though lower) with the screening coverage levels in Nigeria and most of sub-Saharan Africa which is generally below $10 \%$ [22]. The screening coverage ranges from 5.2\% in Ibadan, $4.7 \%$ in Ago-Iwoye, $8.7 \%$ in Sagamu,and $4.4 \%$ in Sokoto [31-34]. Ago-Iwoye is a university town, while Sagamu is home to the teaching hospital. Ago-Iwoye and Sagamu are both in Ogun State.

The most important barrier to cervical screening is lack of awareness and knowledge of cervical cancer and screening. This finding has been underlined by various other findings across local and regional boundaries [35-39]. However, there are studies that suggest that awareness and knowledge of cervical cancer and screening do not necessarily translate to uptake of cervical screening services [40]. They suggest the influence of the other factors. Indeed, other factors found to be barriers to cervical screening among respondents are lack of interest and lack of access to screening. Poor quality of service, cost, culture and lack of interest were not found to be barriers were not found to be barriers to cervical screening among the study groups. While the barriers to screening are supported by evidences from many other studies [12, 17, 35, 36, 38, 40-43], Cost [35, 44] and quality of services $[37,45]$ were indicated by other studies as important barriers to cervical screening uptake by women. These may not be important barriers for the study groups because they are only relevant for those who seek cervical screening which is not the case in our study. The majority of the respondents are not even aware of cervical screening. A study among student $\mathrm{s}$ in a Ghanaian college identified lack of belief that cervical screening will diagnose cervical cancer, pain and the fear of loss of virginity as barriers to uptake of screening services [46]. Other barriers include lack of time [41, 45] culturally relevant beliefs and behaviours [40, 44]. 
V. Tables

Table 1: Awareness of Cervical Cancer and screening

\begin{tabular}{lll}
\hline & Yes $(\mathbf{\%})$ & No $(\%)$ \\
Awareness of cervical cancer & $131(6.5)$ & $1869(93.5)$ \\
Awareness of cervical screening & $96(4.8)$ & $1904(95.2)$ \\
Sources of awareness of cervical cancer and screening & cervical cancer & cervical screening \\
Health Professionals & $56(43.4)$ & $53(56.4)$ \\
Friends/Relatives & $15(11.6)$ & $10(10.6)$ \\
Mass Media & $51(39.5)$ & $27(28.7)$ \\
School & $2(1.6)$ & $2(2.1)$ \\
Public lecture & $2(1.6)$ & $2(2.1)$ \\
Others & $3(2.3)$ & $0(0)$. \\
\hline
\end{tabular}

Table 2: Knowledge of cervical cancer

\begin{tabular}{|c|c|c|c|}
\hline knowledge of cervical cancer & Correct $(\%)$ & Wrong (\%) & Don't know (\%) \\
\hline \multicolumn{4}{|l|}{ Identification of risk factors } \\
\hline family history & $20(1.0)$ & $55(2.8)$ & $1925(96.3)$ \\
\hline Smoking & $40(2.0)$ & $39(2.0)$ & $1921(96.1)$ \\
\hline multiple sexual partners & $80(4.0)$ & $8(0.4)$ & $1912(95.7)$ \\
\hline Virginity & $60(3.0)$ & $23(1.2)$ & $1917(95.9)$ \\
\hline hormonal contraception use & $43(2.2)$ & $28(1.4)$ & $1929(96.5)$ \\
\hline proper and regular condom use & $54(2.7)$ & $24(1.2)$ & $1922(96.2)$ \\
\hline poor diet & $25(1.3)$ & $50(2.5)$ & $1925(96.3)$ \\
\hline HIV/AIDS & $53(2.7)$ & $25(1.3)$ & $1922(96.2)$ \\
\hline \multicolumn{4}{|l|}{ Identification of symptoms } \\
\hline No Symptom & $39(2.0)$ & $37(1.9)$ & $1924(96.1)$ \\
\hline Vaginal Bleeding & $54(2.7)$ & $11(0.6)$ & $1935(96.8)$ \\
\hline Vaginal mass & $57(2.9)$ & $15(0.8)$ & $1928(96.3)$ \\
\hline Weight loss & $51(2.6)$ & $21(1.0)$ & $1928(96.5)$ \\
\hline Back pain & $36(1.8)$ & $33(1.7)$ & $1931(96.6)$ \\
\hline Fracture & $28(1.4)$ & $42(2.1)$ & $1930(96.6)$ \\
\hline Leg pain & $31(1.6)$ & $41(2.1)$ & $1928(96.5)$ \\
\hline Leg swelling & $37(1.9)$ & $32(1.6)$ & $1931(96.6)$ \\
\hline Loss appetite & $40(2.0)$ & $35(1.8)$ & $1925(96.3)$ \\
\hline Urine/faecal leakage & $35(1.8)$ & $26(1.3)$ & $1939(97.0)$ \\
\hline \multicolumn{4}{|c|}{ Identification of method of prevention } \\
\hline Male circumcision & $21(1.1)$ & $44(2.2)$ & $1935(96.8)$ \\
\hline Virginity & $46(2.3)$ & $24(1.2)$ & $1930(96.6)$ \\
\hline hormonal contraception use & $35(1.8)$ & $1991.0)$ & $1946(97.3)$ \\
\hline proper and regular condom use & $48(2.4)$ & $20(1.0)$ & $1932(96.7)$ \\
\hline Proper diet & $38(1.9)$ & $32(1.6)$ & $1930(96.6)$ \\
\hline Immunization & $62(3.1)$ & $10(0.5)$ & $1928(96.5)$ \\
\hline Screening & $82(4.1)$ & $4(0.2)$ & $1914(95.8)$ \\
\hline Smoking & $62(3.1)$ & $6(0.3)$ & 1932 (96.7) \\
\hline
\end{tabular}

Table 3: knowledge about cervical screening

\begin{tabular}{llll}
\hline knowledge about cervical screening & Yes (\%) & No (\%) & Don't know (\%) \\
\hline Can screening prevent cervical cancer & $82(4.1)$ & $14(0.7)$ & $1904(95.2)$ \\
Can screening detect early disease? & $80(4.0)$ & $11(0.6)$ & $1909(95.4)$ \\
Is disease curable if detected early? & $83(4.2)$ & $4(0.2)$ & $1913(95.6)$ \\
\hline
\end{tabular}


Table 4: Perception of the major barrier to uptake of cervical screening

\begin{tabular}{lll} 
The major barriers & Frequency & Percentage \\
\hline Lack of awareness & 1884 & 95.5 \\
Lack of interest & 36 & 1.8 \\
Lack of access to screening services & 16 & 0.8 \\
Too expensive & 16 & 0.8 \\
Poor quality of health services & 10 & 0.5 \\
Others & 12 & 0.6 \\
\hline
\end{tabular}

\section{Conclusion}

The level of awareness of cervical cancer and screening is low in among adult women (20-64 years) in Ogun State Nigeria. The knowledge of risk, symptoms and prevention is also very poor. The women know next to nothing about cervical screening. Consequently, the uptake of cervical screening services is quite low. The major barrier to cervical screening among adult women in Ogun State, Nigeria is lack of awareness and knowledge about cervical cancer and screening. In order to step up the campaign for the control of cervical cancer in Nigeria, it is therefore very important to concentrate much of the effort on creation of awareness and enhancing the knowledge of women about cervical cancer and screening.

\section{Acknowledgements}

We wish to acknowledge the Union for International Cancer Control, Geneva Switzerland that provided the grant that funded this project. We also recognise the 12 Research Assistants who worked tirelessly to ensure its success. Professor O.A Dada is also appreciated for his guidance.

\section{References}

[1]. WHO/ICO Information Centre on HPV and Cervical Cancer (HPV Information Centre). Human Papilloma virus and Related Cancers in Nigeria. Summary Report 2010. Geneva. World Health Organisation. 2010.

[2]. Marrazzo JM, Koutsky LA, Kiviat NB, Kuypers JM, Stine K. "Papanicolaou test screening and prevalence of genital human papilloma virus among females who have sex with women". American Journal of Public Health. 2001; 91(6): 947-52.

[3]. Gottlieb, Nicole. "A Primer on HPV". Benchmarks. Bethesda, USA. National Cancer Institute. 2002. http://www.cancer.gov/newscenter/benchmarks-vol2-issue4/page2. Accessed on February 12, 2012.

[4]. Kumar, Vinay; Abbas, Abul K; Fausto, Nelson \& Mitchel, Richard N (eds). (2007) Robbins Basic Pathology.8th Edition. London. WB Saunders Elsevier. 2007: 718-721.

[5]. Zayyan M. Cervical Cancer in Northern Nigeria; A Preventable Tragedy. Journalist advocacy on tobacco and health. Available at http://jathnigeria.blogspot.com. Accessed on June 24, 2011.

[6]. Royal Thai College of Obstetricians and Gynaecologists (RTCOG)/JHPIEGO Cervical Cancer Prevention Group. Safety, acceptability, and feasibility of a single-visit approach to cervical cancer prevention in rural Thailand: a demonstration project. The Lancet. 2003; 361:814-820.

[7]. DeMay, M. Practical principles of cytopathology. Revised edition. Chicago, IL. American Society for Clinical pathology Press. 2007. ISBN 978-0-89189-549-7.

[8]. Erstad Shannon. "Cone-biopsy (conisation) for abnormal cervical cell changes". WebMD. http://www.webmd.com/cancer/cervicalcancer/cone-biopsy-conisation-for-abnormal-cervical-cell-changes. Accessed on December 2, 2011

[9]. Dolson, Laura (2001). "Trachelectomy". place of public. Publisher. Year. http://www.baymoon.com/gyncancer/library/glossary/bldeftrachelect.htm. Accessed on December 2, 2011

[10]. US Food and Drug Administration. "FDA Approves First Drug Treatment for late stage Cervical Cancer". Place. US Food and Drug Administration. 2006 May. (2006-06-15). http://www.fda.gov/bbs/topics/NEWS/2006/NEW01391.html. Accessed on Dec 2, 2011

[11]. Taofeek I. Research Methodology and Dissertation Writing for Health and Allied Health Professionals. Abuja. Caress Global Link Limited 2009: 75 .

[12]. Ezem BU. Awareness and uptake of cervical cancer screening in Owerri, South-Eastern Nigeria. Annals of African Medicine. 2007 Sep; 6(3): 94-8.

[13]. Ogun GO, Bejide R. "Cervical Cancer in Nigeria, Still a Dismal Story: the Poor State of Cervical Cytology Screening, Factors Responsible for Continuous High Incidence of Cervical Cancer and Hope for Improvement". UICC World Cancer Congress. Washington DC, USA. 2006.

[14]. Nnodu O, Erinosho L, Jamda M, Olaniyi O, Adelaiye R, Lawson L. et al. Knowledge and attitudes towards cervical cancer and human papilloma virus: a Nigerian pilot study. African Journal of Reproductive Health Mar 2010; 14(1):95-108

[15]. Feyi-Waboso PA, Kamanu C, Aluka C. Awareness and risk factors for cervical cancer among Women in Aba, south-eastern Nigeria. Tropical Journal of Obstetrics and Gynaecology. 2005; 22(1):25-26.

[16]. Awodele O, Adeyomoye AAA, Awodele DF, Kwashi V, Awodele O and Dolapo DC A Study on Cervical Cancer Screening Amongst Nurses in Lagos University Teaching Hospital, Lagos, Nigeria J Cancer Educ. 2011 Sep; 26(3):497-504.

[17]. Ayinde OA, Omigbodun AO, Ilesanmi AO. Awareness of cervical cancer, Papanicolaou smear and its utilisation among female undergraduates in Ibadan. Afr J Reprod Health. 2004 Dec; 8(3):68-80.

[18]. Udigwe G.O. Knowledge attitude and practice of cervical cancer screening among female nurses in Nnewi, southeast, Nigeria. Niger. J. Clin Pract. 2006 Jun; 9(1): 40-3.

[19]. Gharoro EP, Ikeanyi EN. An appraisal of the level of awareness and utilization of the Pap smear as a cervical cancer screening test among female healthcare workers in a tertiary health institution. Intl. Journal of Gyn. Cancer. 2006 May; 16(3): 1063-8.

[20]. Hoque ME. Cervical Cancer Awareness and Preventive Behaviour among Female University Students in South Africa. Asian Pac J Cancer Prev. 2010; 11(1):127-130. 
[21]. Nwankwo KC, Aniebue UU, Aguwa EN, Anarado AN, Agunwah E. Knowledge attitudes and practices of cervical cancer screening among urban and rural Nigerian women: a call for education and mass screening. Eur J Cancer Care. 2011 May; 20(3):362-7.

[22]. Wamai RG, Ayissi CA, Oduwo GO, Perlman S, Welty E, Manga S et al. Assessing the Effectiveness of a Community-Based Sensitization Strategy in Creating Awareness about HPV, Cervical Cancer and HPV Vaccine Among Parents in North West Cameroon. J Community Health. 2012 Feb 3. [Epub ahead of print] PMID 22302651.

[23]. Kabir M, Iliyasu Z, Abubakar IS,Mahboob S Awareness and Practice of Cervical Cancer Screening among female professional health workers in Murtala Mohammed Specialist Hospital Kano. Nig Postgrad. Med J. 2005 Sept 12(3):179-82.

[24]. Urasa M, Darj E. Knowledge of cervical cancer and screening practices of nurses at a regional hospital in Tanzania Afr Health Sci. 2011 March; 11(1):48-57.

[25]. McCarey C, Pirek D, Tebeu PM, Boulvain M, Doh AS, Petignat P. Awareness of HPV and cervical cancer prevention among Cameroonian healthcare workers. BMC Women's Health. 2011 Oct; 18:11:45.

[26]. Wright KO, Faseru B, Kuyinu YA, Faduyile FA. Awareness and uptake of the Pap smear among market women in Lagos, Nigeria Journal of Public Health in Africa. 2011; 2(1):58-62.

[27]. Roy B, Tang TS. Cervical cancer screening in Kolkata, India: beliefs and predictors of cervical cancer among women attending a women's health clinic in Kolkata, India. Journal of cancer education. 2008; 23(4):253-259.

[28]. Tiro JM, Meissner HI, Kobrin S, Chollette V. "What do women in the US know about human papillomavirus and cervical cancer?". Cancer Epidemiol. Biomarkers Prev.2007; 16(2): 288-94

[29]. World Health Organization Report (WHO), 2000

[30]. World Health Organization Report (WHO), Control of cancer of the cervix uteri. A WHO meeting, Bulletin of the World Health Organization 1986, 64(4): 607-618

[31]. Ogunbodede OO, Ayinde OA, Awareness of Cervical Cancer and Screening in a Nigerian Female Market population. Annals of African Medicine. 2005; 4(4) 160-3.

[32]. Ogunbowale T, Lawoyin TO. Cervical Cancer risk factors and predictors of cervical dysplasia among women in south-west, Nigeria, Aust. Jour of Rural health, 2008 Dec, 16(6):338-42.

[33]. Adefuye P. Knowledge and Practice of Cervical Cancer Screening among female professional health workers in a sub urban district of Nigeria. Nigerian Medical Practitioner. 2006; 50(1):19-22.

[34]. Nwobodo EI, Malami SA. Knowledge and Practice of cervical screening among female health workers in Sokoto, North-West Nigeria. Nig postgrad. Med J. 2005 Jul; 14(3):283-286.

[35]. Were E, Nyaberi Z, Buziba N. Perceptions of risk and barriers to cervical cancer screening at Moi Teaching and Referral Hospital (MTRH), Eldoret, Kenya Afr Health Sci. 2011 March; 11(1):58-64.

[36]. Leung SKK, Leung I. Cervical cancer screening: knowledge, health perception and attendance rate among Hong Kong Chinese women International Journal of Women's Health Published July 2010;2:221 - 228

[37]. McFarland DM. Cervical cancer and Pap smear screening in Botswana: knowledge and perceptions. International Nursing Review. 2003; 50(3):167-175.

[38]. Ansink AC, Tolhurst R, Haque R, Saha S, Datta S, van den Broek NR. Cervical cancer in Bangladesh: community perceptions of cervical cancer and cervical cancer screening. Trans R Soc Trop Med Hyg. 2008 May; 102(5):499-505.

[39]. Fort VK, Makin MS, Siegler AJ, Ault K, Rochat R. Barriers to cervical cancer screening in Mulanje, Malawi: a qualitative study. Patient Prefer Adherence. 2011; 5:125-131

[40]. Gu C, Chan CWH, Twinn S, Choi KC. The influence of knowledge and perception of the risk of cervical cancer on screening behavior in mainland Chinese women. Psycho-Oncology. 2011 Aug. doi: 10.1002/pon.2037

[41]. Arulogun OS, Maxwell OO. Perception and utilization of cervical cancer screening services among female nurses in University College Hospital, Ibadan, Nigeria. The Pan African Medical Journal. 2012; 11:69.

[42]. Yu CK, Rymer J. Women's attitudes to and awareness of smear testing and cervical cancer. Br J Fam Plann. 1998 Jan; 23(4):12733.

[43]. Ngugi $\mathrm{CW}$, Boga $\mathrm{H}$, Muigai AW, Wanzala P, Mbithi JN. Factors affecting uptake of cervical cancer early detection measures among women in thika, Kenya. Health Care Women Int. 2012 Jul; 33(7):595-613.

[44]. Lynne SL, Low LK. Perceptions of risk for breast and cervical cancer among lesbians: The disparity of knowledge and health care. 128th Annual meeting of APHA Boston, MA. November 13, 2000.

[45]. Walsh, JC. An evaluation of an intervention to improve attendance rates for cancer screening in the Irish Cervical Screening Programme (ICSP). National Institute of Health Sciences Research Bulletin. 2003; 2(1):32-33.

[46]. Abotchie PN, Shokar NK. Cervical Cancer Screening Among College Students in Ghana: Knowledge and Health Beliefs. Int J Gynecol Cancer. 2009 April; 19(3):412-416. 